\title{
Cultural Competency in Haitian-Serving Community Health Centers in South Florida
}

\author{
David Campbell
}

\begin{abstract}
The purpose of this research was to explore the perspectives of health care administrators, practitioners and patients regarding the role and operationalization of cultural competency in their organizations. This work was conducted in three Haitian-serving Community Health Centers (CHCs) in South Florida. CHCs were established in the United States to provide services to underinsured individuals. In recent years cultural competency discourse has become prominent in these institutions through the establishment of federal regulations mandating these programs. The data was collected primarily through ethnographic methods: interviews and participant observation. Conversational interviews were held with the following groups of informants: staff, patients and members of the community at large. Semistructured interviews were held with 15 physicians and administrators of the centers. Unexpectedly, institutions largely devalued cultural competency and were able to sidestep federal regulations by hiring Haitian staff. However, through interactions with patients, it was discovered that aspects of cultural competency were in fact important to them. The qualities they most desire in physicians are: accessibility, linguistic proficiency, and the ability to treat them as individuals within their cultural context. "Cultural humility" is proposed as the resolution to this dilemma. Cultural humility involves a redefining of medicine's understanding of culture. It does not involve complex training programs or the hiring of physicians who are similar to the patient population, but is patient-centered medicine, practiced reflexively. This approach is proposed to improve communication without the undesirable assumptions and effects of the cultural competency paradigm.
\end{abstract}

\section{INTRODUCTION}

The Public Health Agency of Canada has published what they feel to be the 12 key determinants of health (1). Over the years there has been an important debate about the relative importance of each of these to overall health status. Through medical and academic discourse of these determinants, several medical experts have posited that culture is a major contributor to the health of immigrant populations (2-4). It has been postulated

*To whom correspondence should be addressed: Dr. Justin Woodson LTC, MC, SFS, US Army Uniformed Services University of Health Sciences Bethesda, MD

Email: justin.woodson@us.army.mil that minorities have poorer access to health care because of cultural incompatibilities with the health care system and with their individual providers. This spawned the notion of "Cultural Competency" - the idea that medical practitioners can tailor their care for a given cultural group if they gain an adequate understanding of the culture.

The notion of cultural competency became popular among physicians and administrators who work in clinics in large urban centres with significant minority groups. Many of these clinics have targeted members of particular communities by claiming to provide culturally competent services for that specific group. Cultural competency gained importance in highly Haitian-populated areas of South Florida, as cultural incompatibility is a frequently-cited barrier 
to health care for this population (5-6). It has been proposed that increasing cultural competency among practitioners could effectively address this barrier to adequate health care (7).

Two authors (8) have traced the appearance of the term "cultural competency" in medicine to a single publication by psychologist Paul Pedersen in 1988 (9). In the decade that ensued, many articles were published in both medical and anthropological journals, attempting to define cultural competency, and stressing its importance. In order to provide culturally competent care, it is requisite to define what is understood by the term culture. The medical understanding of culture is drastically different from that used in anthropological circles. Anthropologists feel that clinicians and medical researchers are prone to simply culture to distil it to a list of beliefs held by a given ethnic group. This definitional discrepancy has caused a debate between anthropologists and clinicians with regards to the importance of cultural competency and how it should be practiced and institutionalized.

Context

This research explored the notion of cultural competency, as embodied in several Community Health Centers (CHCs) that serve Haitian immigrants in South Florida, through an anthropological lens.

Haitians comprise one of the largest ethnic minority groups in South Florida. The area most densely populated with individuals of Haitian descent is Little Haiti - a neighbourhood just north of Downtown Miami with a population of 33,908 (10). The two counties located immediately north of Miami-Dade: Broward and Palm Beach, are also known to have sizeable Haitian populaces.

The majority of Haitian immigrants in this area are uninsured or underinsured (6). In recent decades, several publicly funded $\mathrm{CHCs}$ have been created to improve the provision of medical care and other vital social services to the uninsured and medically underserved populations in highly Haitian-populated areas of South Florida. These $\mathrm{CHCs}$ are distinct from one another in many ways; however each of them treats many indigent Haitians, and claim to provide culturally appropriate care for this population.

Community Health Centers provide an interesting site to examine the use of cultural competency in clinical settings. The $\mathrm{CHC}$ program was initially set up to establish a network of "safetynet providers" for patients with no alternative source of primary care (11). It was thought that this would improve access to preventive services and thereby decrease costly visits to public hospitals' emergency rooms. Susan Shaw, medical anthropologist specializing in culturally appropriate healthcare programming, has written about how the increasing preoccupation with cultural competency has caused CHCs' main objective to shift from being "providers of last resort" towards being "providers of culturally appropriate care" (12). This assertion has substantial implications for the effectiveness of $\mathrm{CHCs}$ and their ability to serve their designated purpose as safety-net providers. Anthropologists have questioned the erroneous assumptions that guide the clinical application of cultural competency, as such assumptions may result in unintended negative outcomes.

\section{REVIEW OF THE LITERATURE}

\section{Support for Cultural Competency}

Several medical anthropologists were instrumental in developing the idea of cultural competency. These applied anthropologists were involved in clinical medicine by "helping health care providers understand cultural differences in health behaviours" (13). These scholars focused on improving medical care through enhancing the physician-patient relationship. This is purportedly accomplished by "translating the understandings of anthropology for health professionals so that their services to patients can be more humanistic, holistic or culture-sensitive" (14).

Arthur Kleinman explains the differences between subjective patient experiences and the objective view of the medical profession through the Explanatory Model of Illness (EM) approach (15). Both patients and providers have individual explanatory models with regards to a given illness episode. Kleinman states that "the interaction between the EMs of patients and practitioners is a central component of health care" (16). These EMs may in some cases be drastically different, which Kleinman proposes can cause problems in the medical interaction. The incompatibility of patient and practitioner EMs, and the repercussions of such, lends support for cultural competency in medicine.

Journals of public health, nursing, psychiatry and clinical medicine are rife with publications that lend support to the further development of cultural competence in these diverse medical settings. Studies show that culturally appropriate care has been positively correlated with better disease outcomes (17) and may encourage proper use of vaccine programs (18). 
Culture has often been cited as the reason patients fail to comply with the instructions of medical professionals. It is thought that if patient and practitioner EMs are dissonant this will negatively affect patient compliance: "the degree of 'match' or 'mismatch' between the patient's expectations and the care the patient receives will ultimately play a substantial role in the patient's compliance with and response to the treatment plan" (19). It is commonly believed that a physician who is trained in cultural competency will understand the particular qualms that might be troubling patients and be able to resolve them, which will in turn improve compliance. Cultural competency has figured prominently in discussions of quality of care within the medical professions over the past 15 years. They have advanced a strong case for the institutionalization of cultural competency.

\section{Critiques of Cultural Competency}

Critical medical anthropology is defined as "the work of anthropology turned upon our own society" (20). Many critical medical anthropologists have analyzed the assumptions made by the promotion of cultural competency models. These assumptions include: the static and isolated nature of culture used in this concept; the ability to define a culture by a certain set of beliefs or practices; and the homogeneity of individuals deemed to be of the same culture. Also important to consider are the repercussions of focusing on such programs.

In order to promote culturally competent care, the medical institution must first define "culture". This is very difficult, as "culture is what various people conceive it to be, and different people perceive it in different ways for different ends" (21). The way in which medicine has used "culture" has been one of the most prominent critiques of the cultural competency movement. Cultural competency frameworks were built upon outdated anthropological definitions of culture where it is seen to be static and essentialist (22). While medical professionals have been devising strategies to increase knowledge of various cultures, anthropological discourse has produced a more nuanced and complex understanding of culture (23). Taylor states that "what 'culture' is taken to mean in these [clinical] contexts is generally quite distant from, if not actually at odds with, the current state of discussions of 'culture' within anthropology" (24). The most current understanding of culture in anthropological circles is one that "draws on diverse sources, depends on borrowings, and is in flux" (25). It is "a dynamic, ongoing process and an emergent product of human interaction" (26). The definition of culture may be seen to be trivial in the context of medicine. However, it is tremendously important as this definition leads to another crucial assumption upon which the policies and practices of cultural competency are built: that cultures are distinct entities with their own definable 'beliefs and practices'. It then becomes possible to delineate the qualities of a given culture. These characteristics can be taught to clinicians thereby producing "culturally competent practitioners". Kleinman states that "cultural competency becomes a series of "do's and don'ts" that define how to treat a patient of a given ethnic background" (22).

The definition of "culture" used in this discourse includes the fallacious assumption that culture is equally and universally shared by all those who are known by a given cultural label. Dreher and MacNaughton claim that "although individuals may belong to the same cultural group, the assumption that they are, in fact, the same is an ecologic fallacy" (27). One's ethnicity is among several factors that can influence beliefs and actions.

The building of cultural competency on a foundation of fallacious assumptions is a serious matter, as emphasizing this type of essentialist cultural distinction can, in fact, disfavour minorities and increase health disparities through the practises of: ethnic risk grouping, victim blaming, covering up the socio-economic roots of health disparities, and leading to decreased patient-provider communication through cultural generalizations.

One rationale for the necessity of culturally competent care is that certain ethnic groups are deemed to be at higher risk for certain diseases. This technique of ethnic risk grouping has been heavily supported by epidemiologists. According to lan Hacking (28), statistics related to humans must always be preceded by the classification of individuals into definable risk groups. Anthropologists are critical about such categorization and purport that 'cultural risk grouping' can essentially pathologize ethnicity (29). Viewed in this way, culture is a risk factor that a physician may check off alongside smoking or engaging in unprotected sex. A very well documented example of this practice and the ensuing marginalization is the classification of Haitians as a risk group in the American AIDS epidemic. (30). The pathologizing of ethnicities can ultimately lead to victim-blaming: when patients are blamed for their own illnesses due to culturallydetermined behaviours. This can be seen as a means of absolving practitioners and institutions of the responsibility to provide the best possible 
care to minority patients, as negative outcomes can simply be attributed to cultural factors. In this light, it could be argued that cultural competency does not improve the provision of health care, but rather, detracts from quality of care.

One of the most harmful effects of victimblaming is that the true root causes of health disparities can be overshadowed. Statements such as: "Culturally competent healthcare systems have the potential to reduce racial and ethnic health disparities" (31), have generated considerable controversy. Health disparities are distributed predictably along the lines of class and socioeconomic status (32-33). Emphasizing the cultural reasons for disease and morbidity can detract attention from true causes of inequalities. Farmer terms this "the conflation of structural violence and cultural difference" (34). Training culturally competent physicians is resource intensive (35). Critics of cultural competency argue that these resources would be better used to support initiatives that reduce socio-economic barriers to health care rather than building up programs that could potentially place blame back onto those affected by poverty and disease.

Finally, it can be argued that cultural competency could be paradoxically detrimental to physician-patient communication. This is illustrated through the Foucauldian notion of the "medical gaze" (36). This can be described as physicians "seeing a 'case' or 'condition' rather than a human being" (37). This concept is intimately tied to issues of power. The medical gaze is defined by Foucault as "the eye that knows and decides, the eye that governs" (38). This means that physicians are endowed with the authority to treat patients however they see fit, according to scientific principles, and patients are often denied a voice in their care. In the medical profession, it is generally acknowledged that gazing is an undesirable habit in medical practise (Davenport, 2000). Yet how cultural competency facilitates gazing is rarely acknowledged. This can happen as a practitioner gains the impression that he has become sufficiently familiar with ailments commonly affecting a given cultural group. Rather than taking the time to talk patients through their concerns, diagnoses can be made hastily since the physician is 'competent' in culture-bound illnesses. The physician is placing his own understanding of the cultural group's explanatory model on the person, rather than exploring the individual's EM in order to provide the quality personalized care that we claim is deserved by each patient, regardless of ethnicity or culture. A cultural competency model that is simplistic and utilizes the "dos and don'ts list" approach, can lead to more gazing in the medicine, and paradoxically, work contrary to its objective of improved clinical communication.

Cultural competency is an issue that is hotly debated with strong arguments both in support and opposition of these programs. Many clinicians and administrators argue that these programs will strengthen physician-patient relationships thereby improving compliance and ultimately producing better disease outcomes (39). Many critical social scientists are of the opinion that these programs are based on overly simplistic and fallacious assumptions about culture and its role in peoples' lives and may in fact result in poorer service provision to these cultural groups (40).

\section{METHODS}

Open-ended qualitative methods were preferentially chosen over preformed questionnaires in this study for several reasons. The strength of qualitative methods is that they are able to explore patient responses in rich detail. A preformed questionnaire is too restrictive in exploring the perceptions and beliefs that were the goal of this research: "Qualitative methods can be used to obtain the intricate details about phenomena such as feelings, thought processes, and emotions that are difficult to extract or learn about through more conventional research methods." (41)

Data for this ethnographic study were gathered during 6 weeks of fieldwork in South Florida. The primary methods of data collection were participant observation and interviews. The researcher volunteered at several $\mathrm{CHCs}$ and was able to observe the administrative aspect of the organizations' operations. The researcher also spent time in waiting rooms observing and conversing with patients. Semi-structured interviews were conducted with clinic administrators and physicians. Conversational interviews were conducted with clinic patients. Interviews and fieldnotes were transcribed and analyzed qualitatively by examining for common themes and codes.

All patient interviews were conducted in HaitianCreole. Verbal consent was obtained from all informants who participated in the study. This study was approved by the research ethics board of the University of Edinburgh's School of Social and Political Sciences and followed all recommended procedures.

\section{RESULTS}

The research revealed that shared views 
of cultural competency were non-existent - this supports the point that culture is much more complex than the medical profession portrays. The notion of cultural competency and how it is embodied both in individual practitioners and within institutions was explored. Each individual physician that was interviewed had unique and diverging understandings of what it meant to be culturally sensitive or competent in the given context.

Surprisingly, the most commonly recurring theme in cultural sensitivity expressed by individual practitioners was that culture was not of primary importance. Several practitioners reduced the importance of cultural differences to linguistic differences. These physicians claimed that if an individual speaks Creole (or if they have a translator) then they are adequately equipped to be equally as effective as a Haitian doctor or one who 'knows' Haitian culture. One physician in particular said that culture or ethnicity is not important but that success was entirely dependent upon the doctor's ability to speak Creole and build a relationship with his patients through empathy and compassion. He said: "they come to me because I make them feel at ease. They are not only my patient but they are my friend. It is only because of that relationship that there are many things that I can gather, that others may not, not because I am Haitian".

A diverging idea that was expressed was the importance of having a basic knowledge of Haitian culture. Individuals who claimed this believed that it helps them to make sense of patients' clinical presentations which differ from those of other Americans. Some said that it also gives them better perspective on how to increase compliance in their patients: "it helps you come from a perspective where you can actually get them to take what you want them to take".

Most physicians who believed in the importance of culture also believed in a "tolerance" approach to Haitian medical beliefs and expressed concern that trying to correct them may engender hostility and resistance. They expressed that they try to be understanding of people's individual beliefs while strongly encouraging people to follow their recommendations. By contrast, one Haitian physician expressed a "corrective" approach. He claimed that his knowledge of Haitian culture and medical beliefs allowed him to rectify peoples' misinformed etiologies and ineffective treatments. He stated that "you can't make them understand unless you speak to them in their language" - he defined "language" as something much deeper than simply words - he meant having an understanding of folk beliefs and how these are verbalized. Essentially, his mastery of this "language" permitted him to translate patient presentations in Creole into a medical diagnosis and he could then provide education and a prescription in the patient's language.

The institutionalization of the federally mandated program of Cultural and Linguistically Appropriate Services (CLAS) in these CHCs was also explored. The researcher expected to find centralized training programs and institutional emphasis on cultural competency. Surprisingly, no trace of such institutional trainings was found. Some informants claimed that this was because cultural competency could only be learned by those who were truly interested in immersing themselves in Haitian culture, not by occasional trainings and corporate slogans. It was also expressed that this type of training would require significant amounts of time and resources.

Instead of investing in training personnel in cultural competency, the researcher found that these centers tended to prefer a 'quick fix' solution to the CLAS standards; in many cases this accomplished through the hiring of Haitian clinical and support staff. This way $\mathrm{CHCs}$ are able to claim to provide culturally competent care without having to do any extra administrative or educational work. This solution is fraught with problems and misguided assumptions. It assumes that because a provider is Haitian his culture is automatically compatible with that of Haitian patients'. This is certainly not necessarily true; many factors could make this unlikely, including education \& socioeconomic status, religion, and length of time in the United States. Many classic ethnographies and social histories of Haiti describe the great divide between educated wealthy citizens and the peasants and slum-dwellers (42). One Haitian physician noted that he often sees this embodied in the actors in the $\mathrm{CHC}$ setting: "they [the Haitian physicians] want to be like French, they are acting like they are above the people they are serving". Clearly, if this is the case, hiring more Haitian physicians is not an adequate response to demands for increased quality of care for patients.

Religion is another factor that could cause a Haitian physician to be less culturally sensitive than a foreign doctor. The traditional religion of the Haitian peasantry is Catholicism coupled with Vodoun (42). The Haitian elite has been characterized as being naive or hostile when it comes to knowledge about Vodoun: "They know 
very little about vodou which they dismiss as odd superstitions of the mass and are sensitive about the subject... They feel that vodou has given a bad name to Haiti" (43). Even if they are familiar with patients' folk beliefs and treatments, a physician who belongs to the elite class may have class or religion-based Anti-Vodoun sentiments and would be more likely to have a personal bias against these beliefs than a foreigner who has no moral ties to this worldview.

The amount of time that one is in the United States also affects the ability of someone labelled Haitian to be culturally sensitive. An example of this is one of the Medical Assistants at a $\mathrm{CHC}$ who serves as a translator for the non-Haitian physicians. In her role as translator, she is expected to be a cultural broker between the patient and the physician. She had immigrated to the US when she was young. When asked about times when patients present with supernatural illnesses she openly admitted that most of the time she has no idea what they are talking about. As the conversation went on, it became apparent that the researcher's knowledge of "cultural illnesses" surpassed hers, even though she was deemed culturally competent simply due to her ethnicity.

Beyond physician conceptions of cultural competency, it was important to find out whether patients had any concept of this issue and whether it was important to them. Approximately $80 \%$ of participants stated that they would rather see a Haitian doctor than a white doctor. Most of the others said that that they had no preference so long as there was a translator present, and a minority stated that they would rather see a non-Haitian physician. Those who would rather see a Haitian physician used certain catch phrases and proverbs to explain why this was important to them: "Jan pa yo se pa jan pa nou" - their ways are not our ways, "lè ou manje manje ou, ou rekonet gou, men lè ou manje manje ou pa konnen ou pa konnen ki gou I genyen" - when you eat your food you recognize the taste, but when you eat food you are unfamiliar with you don't know what taste it has: "genyen maladi ki sèlman nan ras nou" - there are illnesses that are only in our race.

Patient informants were often very passionate about the issue of cultural sensitivity. This was surprising, especially in light of the disregard for CLAS from administrators and some physicians in each of the $\mathrm{CHCs}$. One of the $\mathrm{CHCs}$ was interesting in that despite $40 \%$ of their patient base being Haitian, there is only one full-time physician who speaks Creole. This physician told me that nearly all the Haitian patients request to see him. He is saddened because his schedule is so full and he can no longer accept any new patients. Since he was hired he has been trying to convince the administration to hire more Haitian or Creolespeaking physicians. However, he expressed that they just are not particularly concerned with this issue and feel that the patients are fine seeing American or Hispanic physicians with a translator. These interviews left onewondering why if having a culturally competent physician is so important to Haitian patients, why it is neglected by the physicians and $\mathrm{CHC}$ administrators who serve them.

\section{DISCUSSION}

The researcher intended to take a critical approach to the application of cultural competency in these $\mathrm{CHCs}$ whose primary focus was supposed to be to function as a 'provider of last resort'. However, the position on this issue gradually changed over the course of the research as a result of interactions with $\mathrm{CHC}$ patients and staff. In fact, as a critical medical anthropologist whose role is "to position ourselves squarely on the side of human suffering" (20), the author took on a role of advocacy on behalf of increasing cultural competency, due to the significance of this issue in the eyes of patients and the widespread triviality of it to administrators.

This ethnographic research suggests that cultural and linguistic competency is important in clinical practice, at least for Haitian patients of South Florida CHCs. These clinics' response to CLAS standards - the hiring of a handful of Haitian physicians - seems insufficient to meet patient demands. Shaw states that there is a need to "move beyond straightforward ideas about [physicianpatient] resemblance to develop more complex ways to modify systems of care to better respond to diverse patients (12). It is easy to understand the anthropological critiques of the "list of dos and don'ts" view of cultural competence but it is also important not to ignore the voice of patients who demand some form of cultural consideration. Several solutions to this dilemma have been proposed by anthropologists and clinicians. The resolution that is proposed in this article is a move towards Cultural Humility.

Cultural humility has been proposed as a solution to the cultural competency debate (44). Cultural humility is defined as "an ongoing, courageous, and honest process of self-critique and self-awareness" 


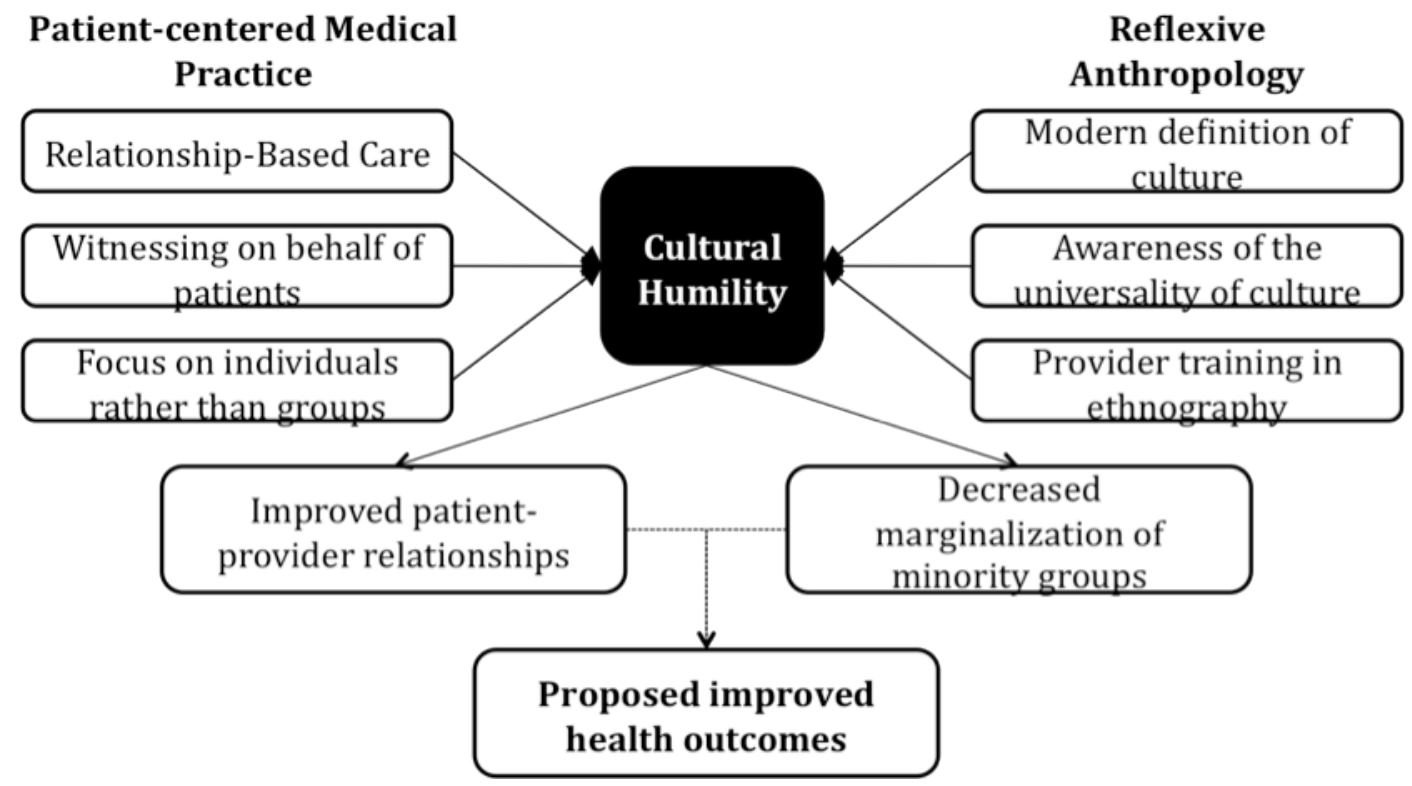

Figure 1: Conceptual Model of Cultural Humility

on the part of medical practitioners (44). The findings of this study show that cultural humility is what patients really demand. They were not looking for a specially trained culturally-competent physician, but were rather looking for a physician who practices medicine in a reflexive manner cognizant of their own culture and open to diverging beliefs of others.

Cultural humility encompasses both the beneficial principles of patient-based medical care and encompasses the suggestions from discussions elicited in modern critical anthropology (See Fig. 1).

The first issue that needs to be addressed is a modernization of the "culture" used in medicine to bring it more in line with contemporary anthropological understandings of the term. This means that culturally humble medical practice recognizes that cultures are not static and are unable to be mastered in such a way as is idealized by the concept of cultural competency. This modern definition of culture also recognizes that cultures are not comprised of a homogenous set of beliefs and practices, and that there is significant and important variation in each member of any given culture. It is imperative that culture be recognized as a universal concept that affects the behaviour of all people: "cultural information is, in fact, embedded in the illness events of all of our patients, not just our "ethnic" patients" (27) and "culture is not just what patients have: clinicians also participate in cultural worlds" (22).
Clinical reflexivity can reduce the power-fraught notion of Foucault's medical gaze (ledema, 2005, SSM). "Witnessing" has been proposed as the opposite to gazing, defined as: "acknowledging the whole lives of the population [physicians] serve" (37). Witnessing only becomes possible through cultural humility of the medical practitioner, or the willingness to relinquish his gaze and his position of power and authority. One of my physicianinformants spoke of this cultural humility:

"Cultural competency is SO difficult to describe. I mean, what does that mean to anybody? How competent can you be in a culture that's not your own? I don't think you need to have that. I think that sensitivity is more important. Willingness to say "ok, they have a different way of seeing things, I'm willing to work with that, not totally oppress or impress my own cultural beliefs on it".

Humility and redefinition of culture can also function to improve the communication between physician and patient as it will lead to an "openness and willingness to seek clarification when patients present with unusual or unfamiliar complaints" (26). By employing a humble approach to culture, medical practitioners are forced to see patients as individuals rather than resorting to generalizations about them based on learned cultural stereotypes. One doctor explained that when you have a relationship with your patients and can communicate with them in their own language, you can understand their personal complaint rather than stereotyping them with your "cultural knowledge". This improved 
communications approach that is facilitated by cultural humility has been termed "relationshipbased care". This care is characterized by physicians who understand that "when compassion and care are conveyed through touch, a kind act, through competent clinical interventions or through listening and seeking to understand the other's experience, a healing relationship is created" (45). It is proposed that the application of cultural humility to the medical system would enhance patientprovider relationships and potentially result in improved health outcomes. If engrained in medical professionals early, these practitioners would not require special training for each individual culture with whom they interact. One proposed method of increasing cultural humility in medical practitioners is to train clinicians in the art and methods of ethnography (22). One of the most effective places to implement this change would be to incorporate such teaching in undergraduate medical curricula. This would mean an increase in emphasis on subjective aspects of the medical interview and on the importance of listening to patients. While many medical curricula already teach these aspects of ethnography, basic instruction in reflexivity is rarely found in the objectively-driven field of western medicine (46). Young medical trainees need to be taught to acknowledge their limitations and biases and to recognize what implications these have on their ability to interpret data from the patient interview. If done effectively, this teaching would allow trainees to gain an appreciation for "the importance of understanding the natives' point of view... appreciating and humanly engaging with their foreignness" (22).

Cultural humility is proposed as the answer to the debate about the importance and effectiveness of the notion of cultural competency. There are significant complexities in medical interactions between individuals of different cultural backgrounds. However, many of these difficulties persist in interactions between providers and patients within the same cultural group. Cultures are not bound, static entities with clearly demarcated features. Attaining a level of competency in another culture is therefore not a realistic expectation. Cultural humility accepts a modern concept of culture and emphasizes relationship-based care where providers acknowledge and consider their own biases. This type of care is proposed to lead to strengthened patient-provider communication and relationships which have been correlated with improved health outcomes.

\section{REFERENCES}

1. Public Health Agency of Canada. What determines health? 2001 [cited 2009 Nov. 13]; Available from: http:// www.phac-aspc.gc.ca/ph-sp/determinants/index-eng. php.

2. Brotanek JM, Seely CE, Flores G. The importance of cultural competency in general pediatrics. Current Opinion in Pediatrics. 2008;20(6):711-18.

3. Betancourt JR. Cultural competency: providing quality care to diverse populations. The Consultant Pharmacist. 2006;21(12):988-95.

4. Rothschild S. Cross-cultural issues in primary care medicine. Disease-a-Month. 1998;44(7):293-319.

5. Stepick A, Stepick C. Preliminary Haitian Needs Assessment. Miami, FL: Center for Labor Research \& Studies, City of Miami; 1995.

6. Little Haiti Community Collaborative. Health Care Needs and Issues in Little Haiti: A Community Voices Project Report. 2004.

7. Brach C, Fraser I. Can Cultural Competency Reduce Racial And Ethnic Health Disparities? A Review And Conceptual Model Medical Care Research and Review. 2000;57(suppl 1):181-217.

8. Martin M, Vaughn B. Cultural Competence: The Nuts and Bolts of Diversity and Inclusion. Strategic Diversity \& Inclusion Magazine. 2007:31-6.

9. Pedersen P. A handbook of develoiping multicultural awareness. Alexandria, VA: American Association for Counseling and Development; 1988.

10. Metellus GM. Miami's Haitian Community. Miami, FL: City of Miami Government; 2004 [cited 200912 January]; Available from: http://www.miamigov.com/haiti2004/ magic.htm.

11. Forrest C, Whelan E-M. Primary Care Safety-Net Delivery Sites in the United States. Journal of the American Medical Association. 2000;284(16):2125-6.

12. Shaw S. The Politics of Recognition in Culturally Appropriate Care. Medical Anthropology Quarterly. 2005;19(3):290-309.

13. McElroy A. Medical Anthropology. In: Levinson D, Ember M, editors. Encyclopedia of Cultural Anthropology. New York: Henry Holt; 1996.

14. Chrisman N, Maretzki T. Clinicially Applied Anthropology. New York: Springer; 1982.

15. Kleinman A. Concepts and a model for the comparison of medical systems as cultural systems. Social Science and Medicine. 1978;12:85-93.

16. Kleinman A. Patients and Healers in the Context of Culture: An exploration of the borderland between anthropology, medicine and psychiatry. Berkeley, CA: University of California Press; 1981.

17. Ortega AN, Calderon JG. Pediatric asthma among minority populations. Current Opinion in Pediatrics. 2000;12(6):579-83.

18. Nichter M. Vaccinations in the third world: A consideration of community demand. Social Science and Medicine. 1995;41(5):617-32.

19. Salimbene S. Cultural Competence: A priority for performance improvement action. Journal of Nursing Care Quarterly. 1999;3(1):23-5.

20. Scheper-Hughes N. Three Propositions for a Critically Applied Medical Anthropology. Social Science in Medicine. 1990;30(2):189-97.

21. Borofsky R, Barth F, Shweder R, Rodseth L, Stolzenberg N. When: A Conversation About Culture. American Anthropologist. 2001;1013(2):432-46.

22. Kleinman A, Benson P. Anthropology in the clinic: The 
problem of cultural competency and how to fix it. Public Library of Science Medicine. 2006;3(10):1673-7.

23. Wright S. The politicization of 'culture'. Anthropology Today. 1998;14(1):7-15.

24. Taylor JS. The story catches you and you fall down: Tragedy, ethnography, and 'cultural competence'. Medical Anthropology Quarterly. 2003;17(2):159-81.

25. Kuper A. Culture: The Anthropologists' Account. Cambridge, MA: Harvard University Press; 2000.

26. Carpenter-Song E, Schwallie MN, Longhofer J. Cultural Competence Reexamined: Critique and Directions for the Future. Psychiatric Services. 2007;58(10):1362-5.

27. Dreher $M$, MacNaughton N. Cultural Competence in Nursing: Foundation or Fallacy? Nursing Outlook. 2002;50:181-6.

28. Hacking I. The Taming of Chance. Cambridge, UK: Cambridge University Press; 1990.

29. Santiago-Irizarry V. Culture as Cure. Cultural Anthropology. 1996;11(1):3-24.

30. Farmer P. AIDS and Accusation: Haiti and the geography of blame. Berkeley: University of California Press; 1992.

31. Anderson LM, Scrimshaw SC, Fullilove MT, Fielding JE, Normand J, The Task Force on Community Preventive Services. Culturally Competent Healthcare Systems: A Systematic Review. American Journal of Preventive Medicine. 2003;24(3S):68-79.

32. Farmer P. Pathologies of Power. Berkeley, CA: University of California Press; 2005.

33. Graham H. Unequal Lives: Health and Socio-economic Inequalities. Maidenhead: Open University Press; 2007.

34. Farmer P. On Suffering and Structural Violence: A View From Below. In: Das V, Lock M, editors. Social Suffering. London: University of California Press; 1997a.

35. Adler NE. Community Preventive Services: Do we know what what we need to know to improve health and reduce disparities? American Journal of Preventive Medicine. 2003;24(3S):10-1.
36. Foucault M. The Birth of the Clinic: Taylor and Francis E-library; 2003.

37. Davenport BA. Witnessing and the Medical Gaze: How Medical Students Learn to See at a Free Clinic for the Homeless. Medical Anthropology Quarterly. 2000;14(3):310-27.

38. Foucault M. The Birth of the Clinic. London: Tavistock Publications Limited; 1973.

39. Betancourt J, Green AR, Carillo J, Park E. Cultural competence and health care disparities: key perspectives and trends. Health Affairs. 2005;24(2):499-505.

40. Lee S, Farrell M. Is cultural competency a backdoor to racism? Anthropology News. 2006;47(3):9-10.

41. Strauss A, Corbin J. Basics of Qualitative Research. Thousand Oaks, CA: Sage Publications; 1998.

42. Leyburn JG. The Haitian People. New Haven, CT: Yale University Press; 1945.

43. Wingfield R, Parenton VJ. Class Structure and Class Conflict in Haitian Society. Social Forces. 1965;43(3):33847.

44. Tervalon M, Murray-Garcia J. Cultural humility versus cultural competence: A critical distinction in defining physician training outcomes in multicultural education. Journal of Health Care for the Poor and Underserved. 1998;9(2):117-25.

45. Koloroutis M. Relationship-Based Care: A Model for Transforming Practice. Minneapolis, MN: Creative Health Care Management; 2004.

46. Novack D, Epstein R, Paulsen R. Toward creating physician-healers: Fostering medical students' selfawareness, personal growth, and well-being. Academic Medicine. 1999;74:516-20. 